\title{
Review
}

\section{Use of $N$-methyl- $N$-nitrosourea treatment of fertilized egg cells for saturation mutagenesis of rice}

\author{
Hikaru Satoh*, Hiroaki Matsusaka and Toshihiro Kumamaru \\ Institute of Genetic Resources, Faculty of Agriculture, Kyushu University, 6-10-1 Hakozaki, Higashi, Fukuoka 812-8581, Japan
}

\begin{abstract}
The efficiency of $N$-methyl- $N$-nitrosourea (MNU) treatment of fertilized egg cells at the single-cell stage in rice (Oryza sativa L.) was about twice that of dry seeds. The proportion of recessive iso-chlorophyll mutants in the segregating progeny of $\mathrm{M}_{1}$ plants decreased remarkably with treatment at later stages of embryonic development, perhaps because of the presence of diplontic selection and chimera formation when older, multicellular embryos were mutagenized. Panicle sterility of the $\mathrm{M}_{1}$ plants showed a linear relationship with the frequency of chlorophyll mutations in the progeny. The mutagenicity of $N$-ethyl- $N$-nitrosourea was similar to that of MNU, but $N$-methyl- $N$ '-nitro- $N$-nitrosoguanidine and $N$-ethyl- $N$ '-nitro- $N$-nitrosoguanidine were less effective. Several thousand rice mutants affecting endosperm, culm length, heading date, and chlorophyll were obtained by MNU mutagenesis. The frequency of certain types of endosperm mutants seemed to differ according to the precise timing of treatment. The mutation rate was calculated as $7.4 \times 10^{-6}$ per nucleotide, and the mutations were evenly distributed over the gene regions examined. These results indicate that our rice mutant library, generated by MNU mutagenesis, is a promising resource for identifying mutations in any rice gene.
\end{abstract}

Key Words: $N$-methyl- $N$-nitrosourea (MNU), mutation, zygotic cell treatment, TILLING, rice (Oryza sativa L.).

\section{Introduction}

Rice (Oryza sativa L.) is one of the most suitable species for post-genomic plant science because, like Arabidopsis thaliana (L.) Heynh., its genome has been fully sequenced. In addition, rice is an important food source, supplying carbon and other nutrients not only to human beings (especially in Asian and African countries) but also to domestic animals. For these reasons, rice has become a model plant not only for fundamental science but also for applied science.

Functional genomics is an important area of post-genomic science that may lead to development of new areas of biotechnology. The quality, quantity, and diversity of available bioresources are key to the quality of biological science research in the post-genome research era. Artificially induced mutations are expected to play an important role in generating bioresources for post-genome science in plants as well as in vertebrates and microbes; the power of such mutations is that they enable comparison of the mutant and corresponding wild-type genes in a genetically uniform background. Therefore, mutagenesis is one of the most effective methods to obtain quantitative and qualitative improvement of bioresources.

Communicated by H. Kitano

Received November 5, 2010. Accepted November 28, 2010.

*Corresponding author (e-mail: hsatoh@agr.kyushu-u.ac.jp)
Various types of mutagens are available to induce mutations in plants. These include radiation such as X-rays, $\gamma$-rays, or UV light; biological mutagens such as T-DNA insertion, transposable elements, or RNAi; and chemical mutagens such as ethyl methanesulfonate (EMS) and nitrosamides (Krishnan et al. 2009). Currently available rice mutant resources include T-DNA insertion lines, Tos 17 (rice transposon) insertion lines, and $A c / D s$ (maize transposon) insertion lines. A wide range and a large number of T-DNA insertion lines (An et al. 2005a, 2005b, Droc et al. 2006, Sallaud et al. 2004, Wu et al. 2003), Tos 17 (rice transposon) insertion lines (Miyao et al. 2003) and $A c / D s$ transposon insertion lines (Machida et al. 1997) have been generated in rice, and the information of flanking sequences have been released. However, the associated problem of these insertion mutants is to include a large number of additional mutations (Suzuki et al. 2008). Transformation of callus usually induces many tissue culture-produced point mutations and deletion mutations. Another problem is that T-DNA and $A c / D s$ lines are transgenic. Several countries restrict severely the cultivation of transgenic materials in the field, limiting the opportunities to utilize these resources. In contrast, Tos 17 and chemically induced mutant lines are easy to generate and handle under field conditions.

Mutations can be classified into the insertional mutation and the point mutation such as SNP (single nucleotide polymorphism) mutation, and there are three types of mutations, 
nonsense (knockout or null), leaky (knockdown), and missense (non-synonymous; nucleotide substitution resulting in amino acid replacement) in the point mutation. In particular, missense mutations will play an important role in functional genomics, not only elucidating the functions of individual genes but also contributing fundamental information in proteomics, metabolomics, and phenomics. The most noteworthy feature of chemical mutagens is their ability to induce dominantly nucleotide substitution mutations. Insertion mutations often produce non-functional proteins that display nearly complete loss of gene function, whereas missense mutations can produce weak, moderate, or severe modifications of protein function, depending on the position and type of amino acid replaced. This characteristic of missense mutations can be very useful for determining which amino acids are important for the function of a protein.

Of the many kinds of chemical mutagens that have been employed to induce nucleotide substitution mutations, nitroso compounds have been reported to be among the most powerful means of inducing mutations in vertebrate and microbial cells. However, the mutagenicity and effectiveness of nitroso compounds has not been well studied in plants. We have induced mutations in rice by treating fertilized egg cells at the single-cell stage in the japonica rice cultivars 'Kinmaze' and 'Taichung 65 ' with the chemical mutagen $N$ methyl- $N$-nitrosourea (MNU), and we have obtained more than ten thousand mutants involved in physiological and morphological traits, including endosperm traits. These mutations should be valuable genetic resources, not only for the basic research but also for the applied science in rice. Targeting Induced Local Lesion In Genomes (TILLING) is a technique to identify single-base-pair allelic variation in a high throughput manner (Till et al. 2003), which was developed as a mutant screening method to take advantage of DNA sequence information and to investigate functions of specific genes (Gilchrist and Haughn 2005, Haughn and Gilchrist 2006, Henikoff et al. 2004). In plants, TILLING combined with EMS-mutagenesis has been used successfully to screen mutant populations induced in Arabidopsis thaliana, and has recently been extended to mutation screening in crops using EMS and/or other chemical mutagens (Caldwell et al. 2004, Slade et al. 2005, Till et al. 2004, 2007, Wu et al. 2005). The modified TILLING system with non-labeled primers and fast capillary gel electrophoresis has been developed and applied for high-throughput detection of singlenucleotide substitution mutations in rice mutant library generated by MNU treatment of the fertilized egg cell (Suzuki et al. 2008). TILLING analysis strongly suggests that this mutant library contains multiple allelic mutants of every gene in the rice genome. In this review, we will summarize briefly the method we have developed for MNU treatment of fertilized egg cells in rice, and we will describe the unique characteristics of the mutant library obtained with this method.

\section{Chemical properties of nitroso compounds}

Nitroso compounds, which include nitrosamides $(N$ alkyl- $N$-nitrosourea, $N$-alkyl- $N$-nitrosourethane, $N$-alkyl- $N$ nitroso-1-napthylcarbamate, etc.), nitrosamidines ( $N$-alkyl$N$ '-nitro- $N$-nitrosoguanidine, etc.), and nitrosamines (dialkyl$N$-nitrosamine, etc.) are some of the most potent mutagens in mammalian and microbial cells. They are $\mathrm{S}_{\mathrm{N}}$ l-type monofunctional alkylating agents with a low Swain-Scott substrate constant $(s)$ (Swain and Scott 1953) and these agents have high reactivity towards centers of low nucleophilicity such as oxygen atom sites in DNA, while $\mathrm{S}_{\mathrm{N}} 2$-type reagents such as EMS and dimethyl sulfate, have a higher $s$ value than $\mathrm{S}_{\mathrm{N}} 1$ reagents and primarily attack sites of high nucleophilicity, such as ring nitrogen atom sites in DNA; they cause little alkylation at the oxygen atom sites (Neale 1976). Mutations by $\mathrm{S}_{\mathrm{N}} 2$ reagents are induced via the error-prone pathway depend on repair system, whereas $\mathrm{S}_{\mathrm{N}} 1$ agents are capable to induce mutations independently from error-prone repair (Neale 1976). In addition, $\mathrm{S}_{\mathrm{N}} 2$ agents intend to cell death caused by reacting with proteins and thus the use of them are mostly limited to dry seeds with low activity of cells in plants.

During decay of nitrosamides, nitrosamidines, and nitrosamines, a common intermediate was formed, namely the diazoalkane, that was the responsible agent during induction of mutations and tumor formation in dimethylnitrosamine (Lijinsky et al. 1968), $N$-methyl- $N$ '-nitro- $N$-nitrosoguanidine (MNNG) (Haerlin et al. 1970, Lingens et al. 1971), MNU (Lawley and Shah 1973), and $N$-ethyl- $N$-nitrosourea (ENU) (Lawley and Warren 1975). Nitrosamides and nitrosamidines are unstable in aqueous solution: their decay is catalyzed by hydroxyl ions and light (Garrett et al. 1965, McCalla et al. 1968). It is therefore necessary to study the mutagenic action of these compounds in the dark in a defined system. Sufficient buffering capacity must be used to counteract any acid production during decay. The decay rates of nitroso compounds are also influenced greatly by temperature.

The mutagenic effect of nitrosamides and nitrosamidines is characterized by specific nucleotide substitution; in particular, the MNU induces predominantly GC to AT transitions, based on data obtained with human cells and E. coli. The mutagenesis of DNA by nitrosamides starts with the methylation of bases, especially guanine and cytosine. $O^{6}$ methylguanine, induced in DNA by MNU treatment, gave rise to GC to AT transition mutations via mispairing with thymine during DNA replication (Cooke et al. 2003, Engelbergs et al. 2000). A number of studies on alkyl nitrosourea induced rodent tumors have shown that methylating $N$-nitroso carcinogens almost exclusively induced GC to AT transitions in the genes analyzed (Calvert et al. 1996, Guzman et al. 1992, Newcomb et al. 1995, Ohgaki et al. 1992, Sukumar et al. 1983, Sukumar and Barbacid 1990, You et al. 1989, Zaidi et al. 1995, Zarbl et al. 1985).

Another unique characteristic of MNU mutagenesis is that its action is tightly associated with DNA replication. 
The number of mutations obtained in bacteria treated with nitroso compounds, including MNNG and MNU, is lower in stationary-phase culture than in growing culture (Adelberg et al.1965, Altenbern 1966, Hince and Neale 1975, Neale 1976). In a synchronized E. coli culture, MNNG-induced mutations did not occur at random throughout the replicating chromosome but were preferentially localized in the region of the replicating fork (Cerdá Olmedo and Hanawalt 1967, 1968, Cerdá Olmedo et al. 1968). Furthermore, this characteristic of MNNG-induced mutations was also observed for MNU and ENU (Hince and Neale 1974), suggesting strongly that nitroso compounds mutated preferentially genes under replication. These findings led to attempt the mapping of gene loci with nitroso compounds (Altenbern 1966).

\section{Treatment of fertilized egg cells of rice with MNU}

Since Muller (1927) and Stadler (1928) first observed the artificial induction of mutations in Drosophila and barley (Hordeum vulgare L.) by X-rays, this method has been adopted to develop novel genetic resources in many plant species. Various mutants have been released and have contributed greatly not only as materials for basic scientific research but also as resources for applied use, such as in crop breeding programs.

Two important goals for mutation induction in plants are to increase the mutation frequency and to control the mutation spectrum. Gaul (1964) and Mericle and Mericle (1967) predicted that a high mutation frequency could be obtained by the irradiation of zygotes at the single-cell stage because it would reduce or eliminate the possibility of chimera formation and diplontic selection (competition of normal and mutant cells within the plant). Gaul (1964) used acute $\gamma$-rays to irradiate both zygote cells of barley after pollination and dry barley seeds and observed that plants grown from the former had about three times as many chlorophyll mutations as those grown from the latter. Despite the effectiveness of radiation as a mutagen, many authors have pointed out that chemical mutagens have an advantage over ionizing radiation because they produce a higher frequency of gene mutations with fewer chromosomal aberrations (Froese-Gertzen et al. 1964, Heiner et al. 1960, Künzel 1971).

In our experiments, we induced mutations by applying various chemical mutagens-MNU, EMS, and ethylene imine (EI) to fertilized egg cells at the single-cell stage in rice and achieved a high mutation frequency with MNU (Satoh and Omura 1979, 1986). Fig. 1A illustrates the procedure we used for MNU treatment, isolation of mutations, and establishment of homozygous mutant lines and Fig. 1B is a photograph of the actual treatment. The panicles were soaked in MNU solution in the dark to avoid the decomposition of MNU by UV ray.

In a series of experiments, two japonica rice cultivars, 'Kinmaze' and 'Taichung 65', and an indica rice cultivar, 'IR36', were used. $\mathrm{MNU}\left(\mathrm{CH}_{3}(\mathrm{NO}) \mathrm{CONH}_{2}\right.$, mol. wt. 103.08) was dissolved in distilled water (DW) in the dark below

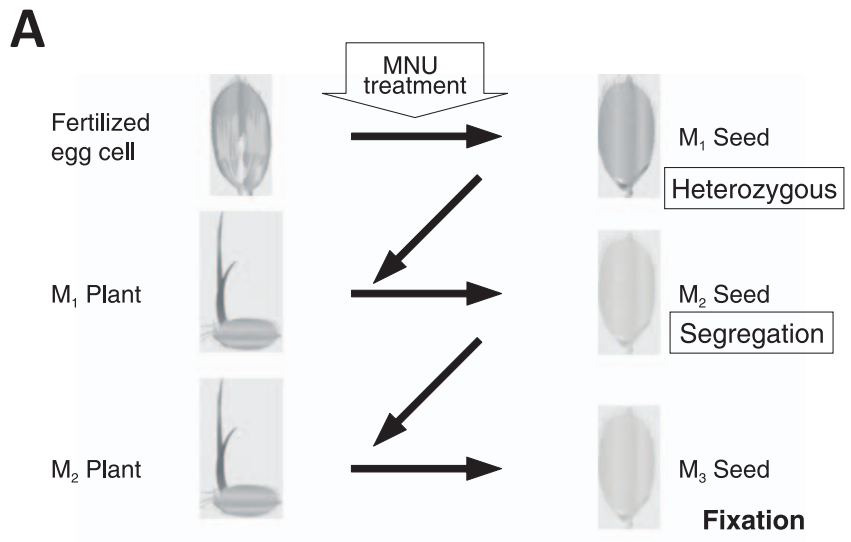

\section{B}

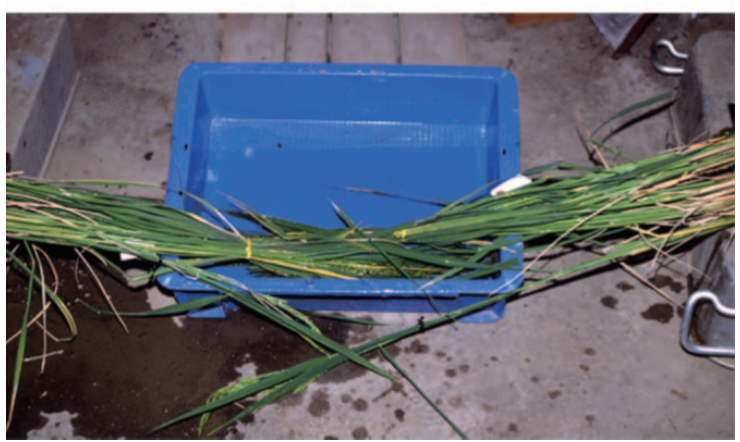

Fig. 1. MNU treatment of fertilized egg cells in rice. (A) Flowchart of MNU treatment procedure. (B) Picture of MNU treatment setup. During actual treatment, the panicles and MNU solution were kept in the dark.

$20^{\circ} \mathrm{C}$, and its $\mathrm{pH}$ was adjusted to $4.8-5.0$ to prevent the decomposition and inactivation of its mutagenic effects (details on $\mathrm{pH}$ stability experiments are given below). To treat the fertilized egg cells with MNU, panicles were prepared as follows. At dusk, 1 to 2 days before treatment, rice plants at the maximum flowering stage were transplanted from the paddy field to plastic pots, and the pollinated spikelets were cut off with scissors. To synchronize the developmental stage of the fertilized egg cells as much as possible, the spikelets that opened for $1 \mathrm{~h}$ from 11:30 to 12:30 were kept for the MNU treatment and the unopened spikelets were cut off. The panicles were exposed to various concentrations of MNU from $0.25 \mathrm{mM}$ to $1.5 \mathrm{mM}$ for 1 to $3 \mathrm{~h}$ at around $24^{\circ} \mathrm{C}$ in the dark. The panicles were rinsed several times immediately after treatment and then washed for more than $24 \mathrm{~h}$ in running tap water under open field as sunlight in day time is expected to accelerate the decay of MNU. More than 500 spikelets were used for each treatment. The progeny of each $\mathrm{M}_{1}$ plant were grown as a separate $\mathrm{M}_{2}$ line, and the segregation of mutants within each line was investigated. Mutant plants in an $\mathrm{M}_{2}$ line showing the same or similar phenotypes were regarded as being caused by a single mutation. Mutation frequency was expressed as the number of mutations per $100 \mathrm{M}_{2}$ lines (\%). 
Table 1. Mutagenetic effects of MNU applied on the fertilized egg cell at 6 hours after flowering and on the dry seed in rice

\begin{tabular}{|c|c|c|c|c|c|c|c|c|c|}
\hline \multicolumn{3}{|c|}{ Treatment } & \multicolumn{5}{|c|}{$\mathrm{M}_{1}$} & \multicolumn{2}{|c|}{$\mathrm{M}_{2}$} \\
\hline Stage & $\begin{array}{l}\text { Conc. } \\
(\mathrm{mM})\end{array}$ & $\begin{array}{l}\text { Period } \\
\text { (h) }\end{array}$ & Seed setting ${ }^{a}$ & Germination $^{a}$ & $\begin{array}{l}\text { Seedling } \\
\text { height }^{a}\end{array}$ & Sterile plant ${ }^{b}$ & Survivals $^{a}$ (a) & $\begin{array}{l}\text { Chlorophyll } \\
\text { mutations (b) }\end{array}$ & $\begin{array}{l}\text { Efficiency } \\
(\mathrm{a} \times \mathrm{b} / 100)\end{array}$ \\
\hline \multirow{7}{*}{$\begin{array}{l}\text { Fertilized } \\
\text { egg cell }\end{array}$} & 0.25 & 1 & 104 & 100 & 100 & 7 & 100 & 3 & 3 \\
\hline & 0.50 & 1 & 103 & 100 & 100 & 8 & 100 & 9 & 9 \\
\hline & 0.75 & 1 & 101 & 100 & 96 & 24 & 97 & 14 & 14 \\
\hline & 1.00 & 1 & 105 & 100 & 100 & 63 & 94 & 23 & 22 \\
\hline & & 2 & 107 & 100 & 81 & 69 & 61 & 49 & 30 \\
\hline & & 3 & 107 & 100 & 86 & 74 & 42 & 47 & 20 \\
\hline & Water & 3 & 100 & 100 & 100 & 0 & 100 & 0 & 0 \\
\hline \multirow{5}{*}{ Dry seed } & 5 & 4 & & 100 & 85 & 6 & 92 & 8 & 7 \\
\hline & 10 & 4 & & 100 & 80 & 28 & 90 & 20 & 18 \\
\hline & 15 & 4 & & 100 & 56 & 45 & 66 & 23 & 15 \\
\hline & 20 & 4 & & 100 & 48 & 47 & 55 & 32 & 18 \\
\hline & Water & 4 & & 100 & 100 & 0 & 100 & 0 & 0 \\
\hline
\end{tabular}

$a \%$ of control (Water)

${ }^{b}$ fertility $<80 \%$

\section{MNU is more mutagenic in growing cells than in dor- mant cells}

The biological effects of MNU treatment applied to fertilized egg cells at $6 \mathrm{~h}$ after flowering and to mature seed are shown in Table 1 . The physiological and mutational effects of MNU were markedly different in the two treatments. The reduction in seedling height was greater in plants grown from treated dry seeds than in those grown from treated fertilized egg cells. On the other hand, more sterile $\mathrm{M}_{1}$ plants (i.e., with fertility $<80 \%$ ) were produced by the latter treatment than by the former. Although the difference in $\mathrm{M}_{1}$ plant survival rate between the two treatments was slight, the causal factors for the survival rate reduction were clearly different. For the treatment of dry seeds, the cause of reduced survival was growth reduction due to poor root growth; for the treatment of fertilized egg cells, the cause of reduced survival was the increased frequency of completely sterility in $M_{1}$ plants. The frequency of $M_{1}$ plant progeny segregating for chlorophyll mutations increased progressively from $3 \%$ to $49 \%$ with increases in either MNU concentration or dosage (concentration of $\mathrm{MNU} \times$ duration of treatment) used to treat fertilized egg cells.

At a dose of $2 \mathrm{mM} \cdot \mathrm{h}$, the efficiency of treatment reached 30 , but it was dropped to 20 at a dose of $3 \mathrm{mM} \cdot \mathrm{h}$ because of the decrease in the survival rate. This result suggests that the dose higher than $3 \mathrm{mM} \cdot \mathrm{h}$ is not desirable to apply to the fertilized egg cells at the mono-cell stage on the induction of mutation with $\mathrm{MNU}$ in rice. Although the frequency of chlorophyll mutations in the treated dry seeds increased with increasing concentrations of MNU, it was considerably lower (maximum of $32 \%$ ) than in the treated fertilized egg cells, despite the much higher concentration of MNU applied to the dry seeds. In addition, the efficiency of the treatment did not increase with concentrations greater than $10 \mathrm{mM}$ because of the decrease in survival in the $\mathrm{M}_{1}$, in spite of the increase in the mutation frequency. These results indicate that the fertilized egg cells are more sensitive to MNU than are the shoot apex cells of dormant seeds. Therefore, treatment of fertilized egg cells is preferable for mutation induction in rice.

There are at least three possible reasons for the high mutation frequency of MNU treatment with fertilized egg cells in rice. The first one is the unique mechanism of mutagenesis of MNU and other nitroso compounds. The number of mutations obtained in bacteria treated with MNNG or MNU was found to be lower in stationary-phase culture than in a growing culture (Adelberg et al. 1965), suggesting that some nitroso compounds are capable of inducing mutations more effectively in actively growing cells than in dormant cells. The second and third reasons (elimination of diplontic selection and decreased frequency of chimeras) are discussed in the following section.

\section{Effects of diplontic selection and chimerism on the mu- tation frequency at different developmental stages}

The second possible reason for an increase in mutation frequency with decreased embryo age is loss of diplontic selection. When a multicellular tissue, such as a shoot apex which consists of four to eight cells, is treated with a mutagen, the recovery of mutated cells in cell division is expected to be delay comparing with that of non-mutated cell because of repairing of DNA injured by mutation treatment, competition can occur between the mutated and non-mutated cells, thus lowering the frequency of mutant cells in the transmission to the next generation. In contrast, when fertilized egg cells are treated at the single-cell stage, all mutations induced by the treatment are expected to be present in the $\mathrm{M}_{1}$ plant unless the original mutated cell dies, because there is no competition between that cell and any other. When we treated embryos at different stages of seed development (from singlecell stage to mature [dry seeds]) with MNU, the frequency of chlorophyll mutations decreased significantly as embryo age 


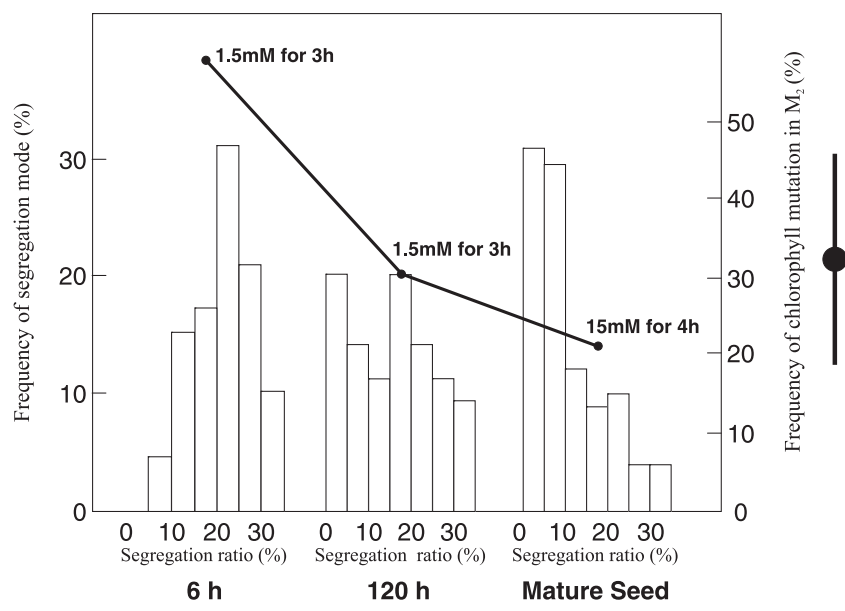

Fig. 2. Frequencies of $\mathrm{M}_{1}$ plants containing chlorophyll mutations and frequencies of recessive chlorophyll mutants in the progeny of $M_{1}$ plants after MNU treatment at different stages of embryonic development. (Left axis and histograms) Frequency distribution of $\mathrm{M}_{1}$ plants showing respective segregation ratio of iso-chlorophyll mutant in the $\mathrm{M}_{2}$ generation. Segregation Ratio : ratio of iso-chlorophyll mutants to total $\mathrm{M}_{2}$ plants derived from individual $\mathrm{M}_{1}$ plants $(25 \%$ is the expected proportion for a single recessive mutation). (Right axis and line) Frequencies of $\mathrm{M}_{1}$ plants with progeny containing a chlorophyll mutation for each embryo development stage indicated. Text above the line indicates MNU concentration and duration used at each embryo development stage tested.

increased (Fig. 2, line graph), even though an increased treatment dose was applied to the dry seeds. These results suggest that diplontic selection may be a factor in decreasing the mutation frequency when mature seeds are treated.

The third possible reason for an increase in mutation frequency in treatments of fertilized egg cells is the inhibition of chimera formation. Even in the absence of diplontic selection, one might expect to see evidence of chimerism (such as altered segregation ratios in the progeny) when multicellular tissues have been mutated. In our study, the frequencies of recessive chlorophyll mutants in the $\mathrm{M}_{2}$ progeny of $\mathrm{M}_{1}$ plants fit well with the theoretical frequency of $25 \%$ (expected for a single recessive gene) when fertilized egg cells were treated $6 \mathrm{~h}$ after flowering (Fig. 2, bar graph). This result indicates that each of the $\mathrm{M}_{1}$ plants derived from the treatment of 6-h-old embryos was derived from a single mutated cell. The mode of the segregation ratio of chlorophyll mutants steadily shifted downwards with the advance in development of the embryo and reached $1 \%$ to $5 \%$ in the treatment of dry seed, suggesting that the size of the mutant sector gradually decreased as the cell number in the embryo or the shoot apex at the time of treatment increased.

The results of this study demonstrated that the smaller size of the mutated sector, possibly combined with elimination of mutated cells due to diplontic selection, is the principle reason for low mutation frequency in the treatment of dry seed, and that the highest mutation frequency is achieved by treating embryos at the single-cell stage.
Table 2. Effects of $\mathrm{pH}$ and temperature on half life (min.) of MNU

\begin{tabular}{crrrrr}
\hline \hline \multirow{2}{*}{$\begin{array}{c}\text { Temperature } \\
\left({ }^{\circ} \mathrm{C}\right)\end{array}$} & $\mathrm{pH} \mathrm{5}$ & $\mathrm{pH} \mathrm{6}$ & $\mathrm{pH} \mathrm{7}$ & $\mathrm{pH} \mathrm{8}$ & $\begin{array}{c}\text { Distilled } \\
\text { water }\end{array}$ \\
\cline { 2 - 6 } & 15,000 & 3,036 & 144 & 18.3 & 5,532 \\
20 & 7,480 & 1,068 & 93 & 13.0 & 3,264 \\
25 & 3,198 & 500 & 46 & 4.5 & 1,398 \\
30 & & & & & \\
\hline
\end{tabular}

\section{Effects of pH on induction of mutations by MNU treat- ment of fertilized egg cells}

As mentioned above, nitroso-alkyl-ureas and nitroso-alkylguanidines are potent mutagens in E. coli, although their decay product, diazoalkane, is postulated as a net active agent during the mutagenesis. The decay of nitroso compounds is catalyzed by hydroxyl ions and light, which may alter both the decay rate and the decomposition products (Neale 1976). Therefore, the $\mathrm{pH}$ of solution containing these nitroso compounds greatly influences the mutation frequency. In studies of $E$. coli, the mutation frequency was tightly correlated with the $\mathrm{pH}$ of the solution: mutation frequency increased as the $\mathrm{pH}$ of the solution increased (Hince and Neale 1974).

To investigate the factors affecting the decay rate of MNU, we dissolved MNU into buffer solutions at different $\mathrm{pH}$ levels and kept the solution at $25^{\circ} \mathrm{C}$ in the dark until the decay rate was measured. The decay rate was estimated by measuring the degree of absorbance at $243 \mathrm{~nm}$, which is the specific absorbance of MNU dissolved in DW. MNU decomposed more rapidly in high-pH solutions than in low-pH solutions, and the half-life of MNU dissolved in the buffer solution adjusted to $\mathrm{pH} 8$ was less than $5 \mathrm{~min}$ at $30^{\circ} \mathrm{C}$ (Table 2). In contrary, MNU dissolved in the $\mathrm{pH} 5$ buffer solution was very stable, with a half-life of more than $200 \mathrm{~h}$ at $20^{\circ} \mathrm{C}$. Usually, $\mathrm{MNU}$ dissolved in $\mathrm{DW}$ is around $\mathrm{pH} 4.8$. As expected, MNU dissolved in DW was much stable, of which the half-life was about $54 \mathrm{~h}$ at $25^{\circ} \mathrm{C}$, one-second of that of MNU dissolved in buffer solutions adjusted to $\mathrm{pH} 5-6$ (Table 2) in the stability. The half-life of the MNU in pH 5 at $20^{\circ} \mathrm{C}$ was three times compared with that of DW, suggesting that the difference may be influenced to the composition in the buffer.

To investigate the optimum $\mathrm{pH}$ level for MNU treatment of fertilized egg cells, fertilized egg cells of rice were treated with $1.0 \mathrm{mM}$ MNU solutions at different $\mathrm{pH}$ levels for $1 \mathrm{~h}$ at around $24^{\circ} \mathrm{C}$. Treatments were carried out at 15 and $18 \mathrm{~h}$ after pollination, with the solution and plant material kept in the dark throughout the treatment period. As shown in Table 3 , the frequency of chlorophyll mutations in the $\mathrm{M}_{2}$ generation decreased markedly with increases in $\mathrm{pH}$ of the MNU solution, with the highest frequency of chlorophyll mutations obtained with the solution at $\mathrm{pH} 5$. This is in contrast to the data reported for E. coli (Hince and Neale 1974), in which the frequency of revertant mutations increased with increasing $\mathrm{pH}$ of the MNU solution. The reason for the 
Table 3. Mutagenic activation of MNU adjusted to different $\mathrm{pH}$ levels by Michaeris phosphate buffer on the treatment of fertilized egg cells in rice

\begin{tabular}{|c|c|c|c|c|c|c|}
\hline Treatment stage $^{a}$ & $\mathrm{pH}$ & $\begin{array}{l}\text { Fertility of treated } \\
\text { panicles }^{b}\end{array}$ & $\begin{array}{l}\text { M } 1 \text { seedling } \\
\text { height }^{b}\end{array}$ & $\begin{array}{l}\text { Fertility of } \mathrm{M}_{1} \\
\text { plant }^{b}\end{array}$ & $\begin{array}{c}\text { Sterile } \\
\mathrm{M}_{1} \text { plant }^{b}\end{array}$ & $\begin{array}{c}\text { Chlorophyll } \\
\text { mutation in } \mathrm{M}_{2}{ }^{b}\end{array}$ \\
\hline \multirow[t]{4}{*}{15 hours } & 5 & 97 & 109 & 50 & 68 & 31 \\
\hline & 6 & 86 & 100 & 54 & 61 & 22 \\
\hline & 7 & 97 & 97 & 69 & 48 & 24 \\
\hline & 8 & 96 & 102 & 97 & 5 & 2 \\
\hline \multirow[t]{4}{*}{18 hours } & 5 & 92 & 96 & 55 & 63 & 33 \\
\hline & 6 & 90 & 103 & 57 & 55 & 26 \\
\hline & 7 & 95 & 98 & 66 & 48 & 23 \\
\hline & 8 & 88 & 108 & 98 & 4 & 2 \\
\hline
\end{tabular}

${ }^{a}$ Time after flowering

$b \%$ of control

difference between the results seen in E. coli and rice is unknown. One possibility is that intracellular conditions may influence the difference in the mutation frequency between rice and $E$. coli. The intracellular environmental conditions, especially $\mathrm{pH}$, or the time it takes for MNU to reach the DNA, like as the alteration in architecture of cell wall by the treatment, may affect the induction of mutations in rice cells.

\section{Action site of nitroso compounds}

As discussed earlier, nitroso compounds act preferentially on the replicating forks of DNA. The mutations induced by MNU and MNNG in a synchronized culture of E. coli did not occur at random throughout the replicating chromosome but were preferentially localized in the region on the replicating fork of DNA (Cerdá Olmedo and Hanawalt 1967, 1968, Cerdá Olmedo et al. 1968). Hince and Neale (1974) observed in the treatment of synchronized culture of $E$. coli with MNU that the number of mutations in each gene at the peak level was five times the number at the basal level. If MNU acts on higher plants in the same manner as on microorganisms, the replicating DNA should mutate at a higher frequency than non-replicating DNA. We observed that the first cell division of the fertilized egg cells of 'Kinmaze' was about $20 \mathrm{~h}$ after pollination under field conditions in Fukuoka, though it varied considerably from year to year because the cell cycle is influenced by the growing conditions, especially temperature. The frequency of chlorophyll mutations was noticeably different among different treatment times, even within the single-cell stage (Fig. 3). The result shown in Fig. 3 suggests that the frequency of mutation induced by MNU is related to the number of replicating point of DNA in the cell cycle.

\section{Spectrum of mutations induced by pulse treatments of zygotic cells with MNU during the single-cell stage}

As mentioned above, MNU acts preferentially the replicating forks of DNA (Hince and Neale 1974) as well as MNNG and thus these mutagenic characteristics of them have been used to the mapping of genes and to verify the origin and

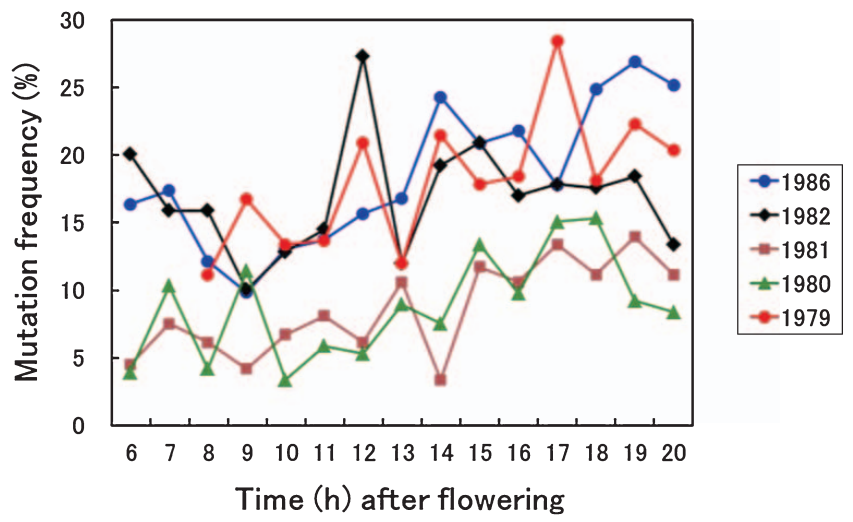

Fig.3. Frequencies of chlorophyll mutations obtained after $\mathrm{MNU}$ treatment of fertilized egg cells at different stages from $6 \mathrm{~h}$ to $20 \mathrm{~h}$ after flowering. Each line represents a different year. (0.75 mM MNU for $60 \mathrm{~min}$. in 1979, $0.5 \mathrm{mM} \mathrm{MNU}$ for $60 \mathrm{~min}$. in 1980, $1.0 \mathrm{mM} \mathrm{MNU}$ for $45 \mathrm{~min}$. in 1981, 1982 and 1986)

time of chromosome replication (Hohlfeld and Vielmetter 1973, Ward et al. 1970).

In the progeny of rice embryos treated with MNU, we have identified mutants for morphological and physiological traits; mutants involved in carbohydrate, lipid, and protein biosyntheses; and mutants that affect embryogenesis (Kumamaru et al. 1988, Satoh and Omura 1986, Satoh et al. 2003). We carried out pulse treatments of zygotic cells with MNU every $2 \mathrm{~h}$ during the single-cell stage and then investigated the spectrum and frequency of endosperm mutations. The frequency of certain mutation types seemed to differ between treatment periods, (e.g., the frequency of giantembryo mutations was highest for treatments 13 to $15 \mathrm{~h}$ after pollination) (Table 4). Although similar results were obtained for treatments carried out in other years, and the results of TILLING analysis seemed to support nonrandomness in the mutation spectra (Suzuki et al. 2008), the differences have not been statistically significant. Control of mutation spectrum is one of the most important goals for the development of novel bioresources by mutation treatment, so it is of interest to investigate whether the mutation spectrum caused by the treatment of fertilized egg cells with 
Table 4. Spectrum and frequency of endosperm mutations induced by the treatment of fertilized egg cells at different stages after flowering with $0.75 \mathrm{mM} \mathrm{MNU}$ for $1 \mathrm{~h}$ at around $24^{\circ} \mathrm{C}$ under the dark

\begin{tabular}{|c|c|c|c|c|c|c|c|c|c|c|c|c|c|c|c|c|c|}
\hline \multirow{2}{*}{ Mutant } & \multicolumn{15}{|c|}{ Treatment stage (hours after flowering) } & \multirow{2}{*}{ Total } & \multirow{2}{*}{$\%$} \\
\hline & 6 & 7 & 8 & 9 & 10 & 11 & 12 & 13 & 14 & 15 & 16 & 17 & 18 & 19 & 20 & & \\
\hline Waxy & & & & & 1 & & 2 & 1 & 1 & 3 & & & 1 & 1 & 1 & 11 & 0.11 \\
\hline Dull & 2 & 1 & 2 & 1 & 1 & & & 2 & 3 & 2 & 3 & 1 & 1 & & 1 & 20 & 0.19 \\
\hline High amylose & & & & & & & 1 & 1 & & & & & 1 & & & 3 & 0.03 \\
\hline Sugary & 1 & 1 & 4 & & 2 & & 1 & 3 & 1 & & 1 & 1 & 4 & 1 & 1 & 21 & 0.20 \\
\hline Shrunken & 1 & 6 & 2 & 4 & 5 & 5 & 5 & 7 & 9 & 5 & 14 & 7 & 4 & 3 & 5 & 82 & 0.79 \\
\hline Floury & 4 & 2 & 6 & 3 & 3 & 2 & 9 & 13 & 14 & 17 & 10 & 8 & 2 & 6 & 7 & 106 & 1.02 \\
\hline White core & 3 & 3 & 8 & 7 & 9 & 7 & 17 & 18 & 20 & 14 & 15 & 13 & 17 & 16 & 9 & 176 & 1.69 \\
\hline Giant embryo & 2 & 2 & 1 & & & 1 & 1 & 4 & 6 & 3 & 1 & & 5 & & & 26 & 0.25 \\
\hline No. of $\mathrm{M}_{1}$ plants & 623 & 748 & 640 & 774 & 1,003 & 766 & 897 & 856 & 792 & 769 & 788 & 620 & 400 & 354 & 375 & 10,405 & \\
\hline
\end{tabular}

Table 5. Relationship between sterility in $M_{1}$ panicle and chlorophyll mutation rate in $M_{2}$ by the fertilized egg cell treatment with MNU

\begin{tabular}{|c|c|c|c|c|c|c|c|c|c|c|c|c|c|c|c|c|c|c|}
\hline & \multicolumn{18}{|c|}{ Sterility in $\mathrm{M}_{1}$} \\
\hline & 0 & ------ & 10 & ------ & 20 & ------ & 30 & ------ & 40 & ------ & 50 & ------ & 60 & ------ & 70 & ------ & 80 & ------- 100 \\
\hline No. of $\mathrm{M}_{1}$ plants & & 3,587 & & 154 & & 278 & & 378 & & 532 & & 446 & & 386 & & 418 & & 272 \\
\hline Mutation in $\mathrm{M}_{2}$ & & 646 & & 62 & & 136 & & 200 & & 282 & & 258 & & 239 & & 292 & & 152 \\
\hline Percentage & & 18 & & 40 & & 49 & & 53 & & 53 & & 58 & & 62 & & 70 & & 56 \\
\hline
\end{tabular}

MNU differs according to the stage in the cell cycle at which treatment is performed.

\section{Mutation frequency in $\mathbf{M}_{2}$ is tightly correlated with the sterility level in $\mathbf{M}_{1}$}

When we treated fertilized egg cells of rice with MNU, we observed a tight correlation between the sterility level of the panicles of $\mathrm{M}_{1}$ plants and the frequency of mutations observed in the $\mathrm{M}_{2}$ generation (Table 5). The frequency of chlorophyll mutations in $\mathrm{M}_{2}$ derived from $\mathrm{M}_{1}$ plants with less than $10 \%$ panicle sterility was very low (about $18 \%$; Table 5). However, the mutation frequency increased as the panicle sterility of the $\mathrm{M}_{1}$ plant increased. The maximum mutation frequency $(70 \%)$ was obtained from plants with $71 \%$ to $80 \%$ panicle sterility. Veleminsky and Gichner (1970) and Fujimoto and Yamagata (1982) observed that panicle sterility in $\mathrm{M}_{1}$ plants was closely related to the mutation frequency in MNU-treated rice. In the present study, most of the seed sterility observed in $M_{1}$ plants was not transmitted to the next generation (data not shown), suggesting that sterility was a temporary effect of MNU treatment rather than a genetic change, although the reason is unknown. In any case, this finding indicates that one can identify mutations most efficiently by preferentially harvesting the sterile $\mathrm{M}_{1}$ plants.

\section{Mutagenicity of nitrosamidines in rice}

The mutagenic effects of ENU, an ethyl derivative of nitrosourea that has been reported as a powerful mutagen in mammalian and microbial cells, were similar to those of MNU (Hince and Neale 1974). Although MNNG and $N$ - ethyl- $N$ '-nitro- $N$-nitrosoguanidine (ENNG), in contrary, have been reported as some of the most powerful mutagens in microbes (Hince and Neale 1974), the response to them appears to differ among plant species (Gichner and Veleminsky 1967, Kamra 1971).

We treated fertilized rice egg cells at the single-cell stage $6 \mathrm{~h}$ after pollination with four kinds of nitroso compounds: the nitrosamides $\mathrm{MNU}$ and ENU, and the nitrosamidines MNNG and ENNG for $1 \mathrm{~h}$ at around $24^{\circ} \mathrm{C}$ under the dark. MNU and ENU were dissolved in DW directly, whereas MNNG and ENNG were dissolved in a small amount of ethanol at first and then diluted by DW. The mutagenic effects of ENU were similar to those of MNU, that is, both treatments were characterized by high mutation frequencies with little injury to the treated seeds or growth reduction in $\mathrm{M}_{1}$ plants (Fig. 4). In contrast, MNNG did not have any mutagenic effects, although it produced severe damage such as a great reduction of seed set in the treated panicles and significant height reduction in the $\mathrm{M}_{1}$ seedlings. The results obtained for ENNG in rice were similar to those obtained with MNNG, of which the treatment gave the very low frequency of chlorophyll mutation in $\mathrm{M}_{2}$ with low level of seed setting in the treated panicles (data not shown), suggesting that nitrosamides are effective for inducing mutations in actively growing cells of higher plants, but the nitrosamidines (at the rates tested) are ineffective for this purpose.

\section{Differences in mutagenesis between $S_{N} 1$ - and $S_{N}$ 2-type mutagens}

The high mutation frequency realized by using the MNU treatment method described here (Fig. 4) is thought to be attributable not only to the use of fertilized egg cells at the 
single-cell stage but also to the mutagenic characteristics of MNU itself. When we treated fertilized egg cells with the $\mathrm{S}_{\mathrm{N}}$ 2-type chemical mutagens, EMS, which is a powerful mutagen when used to treat dry seed of higher plants, the mutation frequencies were significantly lower than those obtained with dry seed treatments, in spite of the higher lethality in treated panicles and severe growth reduction in $\mathrm{M}_{1}$ plants (data not shown). Onozawa (1972) reported that chemical mutagens that have a strong mutagenic effect on dry seed are not always effective for treating growing plants, and they observed that $\mathrm{S}_{\mathrm{N}} 1$-type mutagen, $\mathrm{MNU}$ is a powerful mutagen for treatment of developing embryos.

\section{High efficacy and even distribution of MNU-induced mutations in rice}

TILLING method is one of the most excellent methods to identify the precise mutation frequency per gene loci in the mutation treatment. A modified TILLING system using non-labeled primers and fast capillary gel electrophoresis was applied to high-throughput detection of singlenucleotide substitution mutations in $\mathrm{M}_{2}$ plants derived from MNU treatment of fertilized egg cells at the single-cell stage (Suzuki et al. 2008). The mutation rate of an $\mathrm{M}_{2}$ mutant population was calculated as $7.4 \times 10^{-6}$ per nucleotide, which represents one mutation in every $135 \mathrm{~kb}$ genome sequence. At this frequency, one can expect 7.4 single nucleotide substitution mutations in every $1 \mathrm{~kb}$ of genome sequence when using $1,000 \mathrm{M}_{2}$ mutant lines. The mutations were very evenly distributed over the regions examined. The high frequency of mutation occurrence for the three genes suggested a high probability of identifying multiple mutant alleles for any gene in the genome from an MNU-induced mutant population. The mutant population generated by this method was thus proved to contain mutations at a high frequency, and it should be promising for identifying mutations for every rice gene. These mutant pools should serve as a valuable genetic resource for functional genomics studies in rice.

\section{Type of mutations derived from MNU treatment of fertilized egg cells}

It has been reported that, in microbial and vertebrate cells, MNU induces predominantly GC to AT transitions. Richardson et al. (1987) observed that, after in vivo exposure of $E$. coli to MNU and ENU by using the xanthine guanine phosphoribosyltransferase $(g p t)$ gene as the genetic target, all (39/39) of the MNU-induced mutations were GC to AT transitions.

For three rice genes that we examined in detail, 22 of the 24 nucleotide substitution mutations analyzed (92\%) were transitions of $\mathrm{G}$ to $\mathrm{A}$ or $\mathrm{C}$ to $\mathrm{T}$ (Suzuki et al. 2008). Substitutions from $\mathrm{G}$ to $\mathrm{A}$ and $\mathrm{C}$ to $\mathrm{T}$ were $50 \%$ and $42 \%$, respectively, as expected from alkylation of the guanine residue by MNU (Engelbergs et al. 2000, Jansen et al. 1994, ) and the remaining two were transversions from AT to TA. Similar
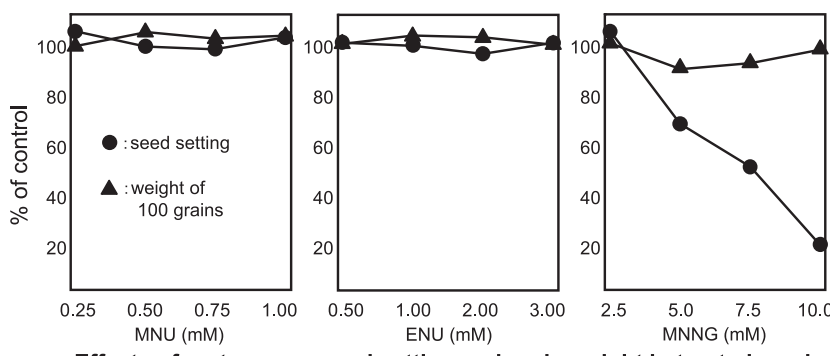

grain weight in tre
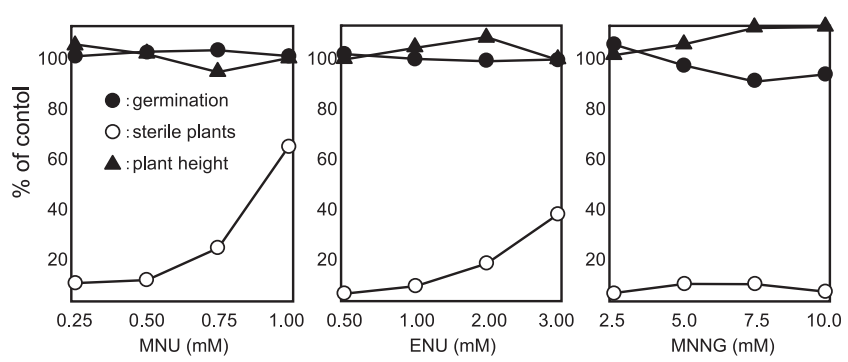

Effects of mutagens on growth habits in $M_{1}$ generation
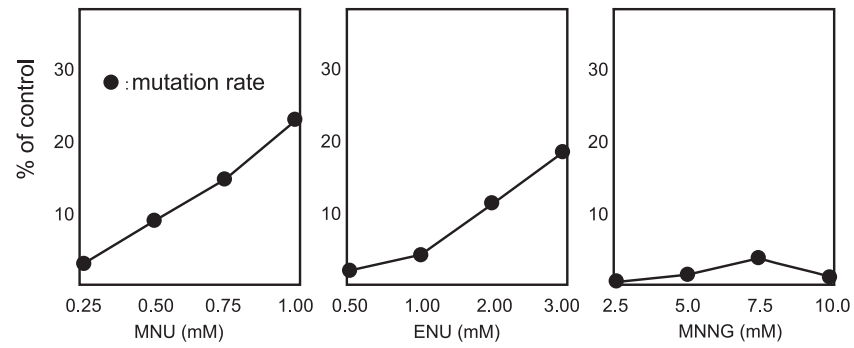

Chlorophyll mutation frequency in $\mathrm{M}_{2}$

Fig. 4. Mutagenic effects of nitrosamides and nitrosamidines on the induction of mutations by the treatment of fertilized egg cells in rice.

results were obtained for mutagenesis of other genes (Satoh et al. 2008, She et al. 2010), providing further evidence that MNU induces predominantly GC to AT transitions in plants, as well as in microbes and vertebrates.

Additional property of MNU mutagenesis is characterized by the high frequency of nonsense mutations derived from the mutations of consensus sequence at the splicing site of intron/exon (Brown 1996), which result the loss of splicing and, in turn, lead to formation of a stop codon by a frame shift in the sequence (Satoh et al. 2008, She et al. 2010), in addition to from the formation of stop codons (Maquat 2004).

\section{Conclusions}

Mutant populations are indispensable genetic resources for functional genomics in all organisms. However, few suitable rice mutant populations have been developed. We report that more than ten thousand mutant lines including morphological, physiological and biochemical traits have been isolated and maintained at Kyushu University. The results of TILLING analysis strongly suggest that this mutant library covers all of the loci in the rice genome; in other words, it appears to represent a saturation mutant library with multiple allelic mutants in rice. 
We have cataloged 6,000 mutant lines derived from the MNU treatment of fertilized egg cell in two japonica cultivars, 'Taichung 65' and 'Kinmaze' during the first phase of National BioResource Project (NBRP) in rice. Mutant seeds can be obtained by requesting them at Oryzabase (http:// www.shigen.nig.ac.jp/rice/oryzabase/top/top.jsp). During the second stage of NBRP, we intend to list mutant lines derived from MNU treatment of cultivar 'Yukihikari', a rice line characterized by its short life cycle under the regulated environmental conditions (growth chamber) and its facile transformation by Agrobacterium tumefaciens and regeneration into transgenic plants.

This library of MNU-induced mutants will be a fundamental functional genomics resource in the identification of mutations in any rice gene and, hence, will complement other available mutant gene resources.

\section{Acknowledgements}

This research was partly supported by the National Bioresource Project, Japan, by the Japan Society for the Promotion of Science, and by the Bio-oriented Technology Research Advancement Institution.

\section{Literature Cited}

Adelberg,E.A., M.Mandel and G.C.C.Chen (1965) Optimal conditions for mutagenesis by $N$-methyl- $N$-nitro- $N$-nitrosoguanidine in Escherichia coli. Biochem. Biophys. Res. Commun. 18: 788-795.

Altenbern,R.A. (1966) Apparent genome mapping of Staphylococcus aureus by a new method. Biochem. Biophys. Res. Commun. 25 : 346-353.

An, G., D.H.Jeong, K.H.Jung and S.Lee (2005a) Reverse genetic approaches for functional genomics of rice. Plant Mol. Biol. 59: 111123.

An, G., S.Lee, S.H.Kim and S.R.Kim (2005b) Molecular genetics using T-DNA in rice. Plant Cell Physiol. 46: 14-22.

Brown,J.W.S. (1996) Arabidopsis intron mutations and pre-mRNA splicing. Plant J. 10: 771-780.

Caldwell,D.G., N.McCallum, P.Shaw, G.J.Muehlbauer, D.F.Marshall and R.Waugh (2004) A structured mutant population for forward and reverse genetics in Barley (Hordeum vulgare L.). Plant J. 40: 143-150.

Calvert,R.J., G.S.Buzard, V.N.Anisimov and J.M.Rice (1996) K-ras codon 12 and 61 point mutations in bromodeoxyuridine and $\mathrm{N}$ nitrosomethylurea-induced rat renal mesenchymal umors. Cancer Lett. 109: 1-7.

CerdáOlmedo,E. and P.C.Hanawalt (1967) Macromolecular action of nitrosoguanidine in Escherichia coll. Biochim. Biophys. Acta 142: 450-464.

CerdáOlmedo,E. and P.C.Hanawalt (1968) The replication of the Escherichia coli chromosome studied by sequential nitrosoguanidine mutagenesis. Cold Spring Harbor Symp. 33: 599-607.

CerdáOlmedo,E., P.C.Hanawalt and N.Guerola (1968) Mutagenesis of the replicating point by nitrosoguanidine: map and pattern of replication of the Escherichia coli chromosome. J. Mol. Biol. 33: 705-719.

Cooke,M.S., M.D.Evans, M.Dizdaroglu and J.Lunec (2003) Oxidative DNA damage: mechanisms, mutation, and disease. FESEB J. 17:
$1195-1214$

Droc, G., M.Ruiz, P.Larmande, A.Pereira, P.Piffanelli, J.B.Morel, A.Dievart, B. Courtois, E. Guiderdoni and C. Perin (2006) OryGenesDB: a database for rice reverse genetics. Nucleic Acids Res. 34: D736-D740.

Engelbergs,J., J.Thomale and M.F.Rajewsky (2000) Role of DNA repair in carcinogen-induced ras mutation. Mutation Res. 450: 139153

Froese-Gertzen,E.E., C.F.Konzak, R.A.Nilan and R.A.Heiner (1964) The effect of ethyl methanesulfonate on the growth response, chromosome structure and mutation in plant breeding. Radiation Botany 4: 61-69.

Fujimoto,M. and H.Yamagata (1982) Studies on the utility of artificial mutations in plant breeding. Jpn. J. Breed. 32: 17-25.

Garrett,E.R., S.Goto and J.E.Stubbins (1965) Kinetics of solvolysis of various $N$-alkyl- $N$-nitrosoureas in neutral and alkaline solutions. J. Pharm. Sci. 54: 119-123.

Gaul,H. (1964) Mutation in plant breeding. Radiation Botany 4: 215232.

Gichner,T. and J.Veleminsky (1967) The mutagenic activity of 1alkyl-1-nitrosoureas and 1-alkyl-3-nitro-1-nitrosoguanidines. Mutation Res. 4: 207-212.

Gilchrist,E.J. and G.W.Haughn (2005) TILLING without a plough: a new method with applications for reverse genetics. Curr. Opin. Plant Biol. 8: 211-215.

Guzman, C., R.C.Osborn, S.M. Swanson, R. Sakthivel, S.I.Hwang, S.Miyamoto and S.Nandi (1992) Incidence of c-Ki-ras activation in $N$-methyl- $N$-nitrosourea-induced mammary carcinomas in pituitary-isografted mice. Cancer Res. 52: 5732-5737.

Haerlin, R., R.Siissmuth and F.Lingens (1970) Mechanism of mutagenesis by $N$-methyl- $N$ '-nitro- $N$-nitroso-guanidine (MNNG). V. Methylation of DNA by $N$-trideuteriomethyl- $N^{\prime}$-nitro- $N$-nitrosoguanidine (D ${ }_{3}$-MNNG). FEBS Lett. 9: 175-176.

Haughn, G.W. and E.J.Gilchrist (2006) TILLING in the botanical garden: a reverse genetic technique feasible for all plant species. In: TeixeiradaSilva,J.A. (eds.) Floriculture, Ornamental and Plant Biotechnology: Advances and Topical Issues, Vol. 1. Global Science Books, London, pp. 476-482.

Heiner,R.C., C.F.Konzak, A.Nilan and R.R.Legault (1960) Diverse ratios of mutations to chromosome aberrations in barley treated with diethyl sulfate and gamma rays. Proc. Natl. Acad. Sci. USA 46: 1215-1221.

Henikoff,V.S., B.J.Till and L.Comai (2004) TILLING. Traditional mutagenesis meets functional genomics. Plant Physiol. 135: 630636.

Hince, T.A. and S.Neale (1974) A comparison of the mutagenic action of the methyl and ethyl derivatives of nitrosamides and nitrosamidines on Escherichia coli. Mutation Res. 24: 383-387.

Hince,T.A. and S.Neale (1975) Effect of Escherichia coli growth rate on the number of mutations induced by $N$-methyl- $N$-nitrosourea. Proc. Soc. Gen. Microbiol. 2: 53.

Hohlfeld, R. and W.Vielmetter (1973) Bidirectional growth of the E. coli chromosome. Nature New Biol. 242: 130-132.

Jansen,J.G., G.R.Mohn, H.Vrieling, C.M.v.Teijlingen, P.H.Lohman and A.A.v.Zeeland (1994) Molecular analysis of hprt gene mutations in skin fibroblasts of rats exposed in vivo to $\mathrm{N}$-methyl- $\mathrm{N}$ nitrosourea or $N$-ethyl- $N$-nitrosourea. Cancer Res. 54: 2478-2485.

Kamra,O.P. (1971) On the differential mutagenic activities of $N$-alkyl$N^{\prime}$-nitro- $N$-nitrosoguanidines in higher plants. Mutation Res. 13: 327-335.

Krishnan,A., E.Guiderdoni, G.An, Y.I.C.Hsing, C.D.Han, M.C.Lee, 
S.M.Yu, N.Upadhyaya, S.Ramachandran, Q.Zhang et al. (2009) Mutant resurces in rice for functional genomics of the grasses. Plant Physiol. 149: 165-170.

Kumamaru,T., H.Satoh, N.Iwata, T.Omura, M.Ogawa and K.Tanaka (1988) Mutants for rice storage proteins. 1. Screening of mutants for rice storage protein bodies in the starchy endosperm. Theor. Appl. Genet. 76: 11-16.

Künzel,G. (1971) The ratio of chemically induced chromosome aberrations to gene mutations in barley. A critical study. Mutation Res. 12: 397-409.

Lawley,P.D. and S.A. Shah (1973) Methylation of DNA by ${ }^{3} \mathrm{H} .{ }^{14} \mathrm{C}-$ methyl-labelled $N$-methyl- $N$-nitrosourea evidence for transfer of the intact methyl group. Chem. Biol. Interact. 7: 115-120.

Lawley,P.D. and W.Warren (1975) Specific excision of ethylated purines from DNA of Escherichia coli treated with $N$-ethyl- $N$ nitrosourea. Chem. Biol. Interact. 11: 55-57.

Lijinsky, W., J.Loo and A.E.Ross (1968) Mechanism of alkylation of nucleic acids by nitrosodimethylamine. Nature 218: 1174-1175.

Lingens,F., F.Haerlin and R. Siissmuth (1971) Mechanism of mutagenesis by $N$-methyl- $N$ '-nitro- $N$-nitrosoguanidine (MNNG). Methylation of nucleic acids by $N$-trideuteriomethyl- $N$ '-nitro- $N$-nitrosoguanidine $\left(\mathrm{D}_{3}-\mathrm{MNNG}\right)$ in the presence of cysteine and in cells of Escherichia coli. FEBS Lett. 13: 241-242.

Machida,C., H.Onouchi, J.Koizumi, S.Hamada, E.Semiarti, S.Torikai and Y.Machida (1997) Characterization of the transposition pattern of the Ac element in Arabidopsis thaliana using endonuclease ISceI. Proc. Natl. Acad. Sci. USA 94: 8675-8680.

Maquat,L.E. (2004) Nonsense-mediated mRNA decay: Splicing, translation and mRNA dynamics. Nat. Rev. Mol. Cell Biol. 5: 8999.

McCalla,D.R., A.Reuvers and R.Kitai (1968) Inactivation of biologically active $N$-methyl- $N$-nitroso compounds in aqueous solution: effect of various conditions of $\mathrm{pH}$ and illumination. Can. J. Biochem. 46: 807-811.

Mericle,L.W. and R.P.Mericle (1967) Mutation induction as influenced by developmental stage and age. In: Induced Mutations and Their Utilization. Akademie-Verlag, Berlin, pp. 65-67.

Miyao, A., K.Tanaka, K. Murata, H.Sawaki, S.Takeda, K. Abe, Y. Shinozuka, K.Onosato and H.Hirochika (2003) Target site specificity of the Tos 17 retrotransposon shows a preference for insertion within genes and against insertion in retrotransposon rich regions of the genome. Plant Cell 15: 1771-1780.

Muller,H.J. (1927) Artificial transmutation of the gene. Science 66: 84-87.

Neale,S. (1976) Mutagenicity of nitrosamides and nitrosamidines in micro-organisms and plants. Mutation Res. 32: 229-266.

Newcomb, W., W.Bayona and S.Pisharody (1995) $N$-methylnitrosoureainduced Ki-ras codon 12 mutations: early events in mouse thymic lymphomas. Mol. Carcinog. 13: 89-95.

Ohgaki,H., G.C.Hard, N.Hirota, A. Maekawa, M.Takahashi and P.Kleihues (1992) Selective mutation of codons 204 and 213 of the p53 gene in rat tumors induced by alkylating $N$-nitroso compounds. Cancer Res. 52: 2995-2998.

Onozawa,Y. (1972) Effects of chemical mutagens applied on growing plants. Gamma Field Symp. 11: 61-72.

Richardson, K.K., F.C.Richardson, R.M.Crosby, J.A.Swenberg and T.R. Skopek (1987) DNA base changes and alkylation following in vivo exposure of Escherichia coli to $N$-methyl- $N$-nitrosourea or $N$-ethyl- $N$-nitrosourea. Proc. Natl. Acad. Sci. USA 84: 344-348.

Sallaud,C., C.Gray, P.Larmande, M.Bes, P.Piffanelli, B.Piegu, G. Droc, F.Regad, E.Bourgeois, D.Meynard et al. (2004) High through- put T-DNA insertion mutagenesis in rice: a first step towards in silico reverse genetics. Plant J. 39: 450-464.

Satoh,H. and T.Omura (1979) Induction of mutation by the treatment of fertilized egg cell with $N$-methyl- $N$-nitrosourea in rice. J. Fac. Agr. Kyushu Univ. 24: 165-174.

Satoh,H. and T.Omura (1986) Mutagenesis in rice by treating fertilized egg cells with nitroso compounds. In: Rice Genetics. Proceedings of the International Rice Genetics Symposium. Agribookstore, Arlington, pp. 707-717.

Satoh,H., A.Nishi, N.Fujita, A.Kubo, Y.Nakamura, T.Kawasaki and T.W.Okita (2003) Isolation and characterization of starch mutants in rice. J. Appl. Glycosci. 50: 225-230.

Satoh,H., K.Shibahara, K.Tokunaga, A.Nishi, M.Tasaki, S.K.Hwang, T.W.Okita, N.Kaneko, N.Fujita, M.Yoshida et al. (2008) Mutation of the plastidic $\alpha$-glucan phosphorylase gene in rice affects the synthesis and structure of starch in the endosperm. Plant Cell 20: 1833-1849.

She,K.C., H.Kusano, K.Koizumi, H.Yamakawa, M.Hakata, T.Imamura, M.Fukuda, N.Naito, Y.Tsurumaki, M.Yaeshima et al. (2010) A novel factor FLOURY ENDOSPERM 2 is involved in regulation of rice grain size and starch quality. Plant Cell (Online first 2010/0x/ yz) doi:10.1105/tpc.107.054007.

Slade, A.J., S.L.Fuerstenberg, D.LoeZer, M.N. Steine and D.Facciotti (2005) A reverse genetic, nontransgenic approach to wheat crop improvement by TILLING. Nat. Biotec. 23: 75-81.

Stadler,L.J. (1928) Mutations in barley induced by X-rays and radium. Science 68: 186-187.

Sukumar, S., V.Notario, D.Martin-Zanca and M.Barbacid (1983) Induction of mammary carcinomas in rat by nitroso-methylurea involves malignant activation of H-ras-1 locus by single point mutations. Nature 306: 658-661.

Sukumar,S. and M.Barbacid (1990) Specific patterns of oncogene activation in transplacentally induced tumors. Proc. Natl. Acad. Sci. USA 87: 718-722.

Suzuki, T., M.Eiguchi, T.Kumamaru, H.Satoh, H. Matsusaka, K. Moriguchi, Y.Nagato and N.Kurata (2008) MNU-induced mutant pools and high performance TILLING enable finding of any gene mutation in rice. Mol. Genet. Genomics 279: 213-223.

Swain,C.G. and C.B.Scott (1953) Quantitative correlation of relative rates. Comparison of hydroxide ion with other nucleophilic reagents toward alkyl halides, esters, epoxides and acyl halides. J. Amer. Chem. Soc. 75: 141-147.

Till,B.J., S.H.Reynolds, E.A.Greene, C.A.Codomo, L.C.Enns, J.E. Johnson, C.Burtner, A.R.Odden, K.Young, N.E.Taylor et al. (2003) Large-scale discovery of induced point mutations with high-throughput TILLING. Genome Res. 13: 524-530.

Till,B.J., S.H.Reynolds, C.Weil, N.Springer, C.Burtner, K.Young, E.Bowers, C.A.Codomo, L.C.Enns, A.R.Odden et al. (2004) Discovery of induced point mutations in maize genes by TILLING. BMC Plant Biol. 4: 12.

Till,B.J., J.Cooper, T.H.Tai, P.Colowit, E.A.Greene, V.S.Henikoff and L.Comai (2007) Discovery of chemically induced mutations in rice by TILLING. BMC Plant Biol. 7: 19.

Veleminsky, J. and T.Gichner (1970) The influence of $\mathrm{pH}$ on the mutagenic effectiveness of nitroso compounds in Arabidopsis. Mutation Res. 10: 43-52.

Ward,C.B., M.W.Hane and D.A.Glaser (1970) Synchronous reinitation of chromosome replication in $E$. coli $\mathrm{B} / \mathrm{r}$ after nalidixic acid treatment. Proc. Natl. Acad. Sci. USA 66: 365-369.

Wu,C., X.Li, W.Yuan, G.Chen, A.Killian, J.Li, C.Xu, X.Li, D.X. Zhou, S. Wang et al. (2003) Development of enhancer trap lines for 
functional analysis of the rice genome. Plant J. 35: 418-427.

Wu,J.L., C.Wu, C.Lei, M.Baraoidan, A.Bordeos, M.R.S.Madamba, M. Ramos-Pamplona, R. Mauleon, A. Portugal, V.J.Ulat et al. (2005) Chemical- and irradiation-induced mutants of indica rice IR64 for forward and reverse genetics. Plant Mol. Biol. 59: 85-97.

You,M., U.Candrian, R.R.Maronpot, G.D.Stoner and M.W.Anderson (1989) Activation of the Ki-ras protooncogene in spontaneously occurring and chemically induced lung tumors of the strain A mouse. Proc. Natl. Acad. Sci. USA 86: 3070-3074.
Zaidi,N.H., T.P.Pretlow, M.A.O'Riordan, L.L.Dumenco, E.Allay and S.L.Gerson (1995) Transgenic expression of human MGMT protects against azoxymethane-induced aberrant crypt foci and $\mathrm{G}$ to $\mathrm{A}$ mutations in the K-ras oncogene of mouse colon. Carcinogenesis 16: 451-456.

Zarbl,H., S.Sukumar, A.V.Arthur, M.Martin-Zanca and M.Barbacid (1985) Direct mutagenesis of H-ras-1 oncogenes by $\mathrm{N}$-nitroso- $\mathrm{N}$ methylurea during initiation of mammary carcinogenesis in rat. Nature 315: 382-385. 